\title{
PEMANFAATAN LIMBAH RUMPUT LAUT Eucheuma cottonii SEBAGAI MEDIUM DENSITY FIBREBOARD (MDF) DENGAN KONSENTRASI PEREKAT YANG BERBEDA
}

\section{The Use of Seaweed Waste Eucheuma Cottonii as Medium Density Fibreboard (Mdf) with the Difference of Adhesive Concentration}

\author{
Moch. Amin Alamsjah ${ }^{1 *}$, Kurnia Ayu K.W ${ }^{2}$ and Boedi Setya Rahardja ${ }^{3}$ \\ ${ }^{1}$ Departemen Kelautan, Fakultas Perikanan dan Kelautan, Universitas Airlangga, Surabaya \\ ${ }^{2}$ Program Studi Budidaya Perairan, Fakultas Perikanan dan Kelautan, Universitas Airlangga, Surabaya \\ ${ }^{3}$ Departemen Manajemen Kesehatan Ikan dan Budidaya Perairan, Fakultas Perikanan dan Kelautan, Universitas \\ Airlangga, Surabaya \\ *alamsjah_fpk@yahoo.com
}

\begin{abstract}
Abstrak
Diperlukan alternatif pengganti penggunaan kayu di dalam pembuatan papan komposit. Salah satu jenis produk papan komposit adalah Medium Density Fibreboard (MDF). Salah satu jenis alternatif yang dapat digunakan sebagai pengganti kayu dalam pembuatan MDF adalah limbah rumput laut Eucheuma cottonii. Penelitian ini bertujuan untuk mengetahui pengaruh perbedaan dan penggunaan konsentrasi perekat yang optimal dalam pemanfaatan limbah rumput laut Eucheuma cottonii sebagai Medium Density Fibreboard (MDF) terhadap pengujian secara fisis dan mekanis. Metode penelitian ini adalah eksperimen dengan rancangan percobaan Rancangan Acak Lengkap (RAL). Perlakuan yang digunakan adalah penambahan konsentrasi perekat, yaitu A (0\%), B (6\%), C (9\%) dan D (12\%), dengan lima ulangan. Parameter yang diamati adalah kerapatan $\left(\mathrm{gr} / \mathrm{cm}^{3}\right)$, kadar air $(\%)$, daya serap $(\%)$, pengembangan tebal $(\%)$, keteguhan lentur $\left(\mathrm{kgf} / \mathrm{cm}^{2}\right)$, keteguhan patah $\left(\mathrm{kgf} / \mathrm{cm}^{2}\right)$ dan kuat pegang sekrup (kgf). Analisis data menggunakan Analisis Ragam (ANOVA) dan apabila terdapat pengaruh terhadap hasil dilakukan uji jarak Duncan. Hasil penelitian menunjukkan bahwa konsentrasi perekat berpengaruh terhadap daya serap air, pengembangan tebal, keteguhan lentur dan keteguhan patah $(\mathrm{p}<0,01)$, namun tidak berpengaruh terhadap kerapatan, kadar air dan kuat pegang sekrup MDF ( $<<0,01)$. Perlakuan terbaik terdapat pada perlakuan D (12\%) dengan nilai kerapatan $0,65 \mathrm{gr} / \mathrm{cm}^{3}$, pengembangan tebal $7,86 \%$, keteguhan lentur $1,68 \times 10^{4} \mathrm{kgf} / \mathrm{cm}^{2}$, keteguhan patah $246,27 \mathrm{kgf} / \mathrm{cm}^{2}$ dan kuat pegang sekrup $34,72 \mathrm{kgf}$ yang secara umum telah memenuhi standar JIS kecuali nilai kadar air dan daya serap air. Perlu dilakukan penelitian lebih lanjut untuk mendapatkan MDF yang memenuhi standar secara sempurna.
\end{abstract}

Kata kunci :Limbah Rumput Laut Eucheuma cottonii, Medium Density Fibreboard (MDF), Konsentrasi Perekat.

\begin{abstract}
Necessary alternative to the use of wood in the manufacture of composite board. One of the type composite board products are Medium Density Fibreboard (MDF). One of the type alternatives that can be used as a substitute for wood in the manufacture of MDF was Eucheuma cottonii waste. The purpose of this study was to determine the effect of the different adhesive concentration and the optimal use of adhesive concentration in the use of seaweed waste Eucheuma cottonii as Medium Density Fibreboard (MDF) on the basis of physical and mechanical testing. The method of this study was experimental with Completely Randomized Design as experimental design. The treatment was completed by adding concentration of adhesive as A $(0 \%), \mathrm{B}(6 \%), \mathrm{C}$ $(9 \%)$ and D (12\%), with five repeatations. Parameters were measured as density $\left(\mathrm{gr} / \mathrm{cm}^{3}\right)$, moisture content $(\%)$, water absorption $(\%)$, thickess swelling $(\%)$, modulus of elasticity $\left(\mathrm{kgf} / \mathrm{cm}^{2}\right)$, modulus of rupture $\left(\mathrm{kgf} / \mathrm{cm}^{2}\right)$ and the hold strength of screw (kgf). Data analysis used Analysis of Varian (ANOVA) and if there was different from result further study by Duncan's Multiple Range Test was needed.The result of this study showed that adhesive concentration had effect on water absorption, thickess swelling, modulus of elasticity and modulus of rupture $(\mathrm{p}<0,01)$, but had no effect on density, moisture content and the hold strength of screw. The best treatment in this study was treatment D $(12 \%)$ with the value of density was $0.65 \mathrm{~g} / \mathrm{cm}^{3}$, thickess swelling was $7.86 \%$, modulus of elasticity was $1.68 \times 10^{4} \mathrm{kgf} / \mathrm{cm}^{2}$, modulus of rupture was $246.27 \mathrm{kgf} / \mathrm{cm}^{2}$ and the hold strength of screw $34.72 \mathrm{kgf}$ which in generally has met the JIS standard except moisture content and water absorption. It is necessary to do further study to get characteristic of MDF whice meet the standard perfectly.
\end{abstract}

Keywords : Seaweed Waste Eucheuma cottonii, Medium Density Fibreboard (MDF), Adhesive Concentration 


\section{PENDAHULUAN}

Produksi rumput laut nasional saat ini mengalami peningkatan yang cukup signifikan. Produksi rumput laut nasional pada tahun 2014 mencapai sekitar 10,2 juta ton atau meningkat lebih dari tiga kali lipat, dimana sebelumnya produksi rumput laut pada tahun 2010 hanya berkisar pada angka 3,9 juta ton (Kementerian Kelautan dan Perikanan, 2015). Menurut Kasim dan Asnani (2012), jenis E. cottonii merupakan jenis rumput laut yang paling banyak dibudidayakan di Indonesia khususnya kawasan timur Indonesia seperti di perairan Sulawesi. Namun tidak semua hasil panen Eucheuma cottonii dapat diekspor sebagai bahan baku kosmetik serta bahan makanan karena ada saja bagian yang tidak masuk kedalam kriteria kelayakan sebagai bahan baku untuk diekspor (Wiratmaja dkk., 2011).

Hutan tropis di Indonesia mempunyai tingkat keanekaragaman hayati yang sangat tinggi baik flora maupun faunanya. Namun keanekaragaman hayati hutan di Indonesia baik pada level ekosistem, jenis dan gen telah dan sedang mengalami ancaman yang sangat serius (Yudohartono, 2008). Saat ini juga kebutuhan bahan papan terus mengalami peningkatan. Meningkatnya pemakaian kebutuhan akan papan ini dapat memberikan pengaruh yang kurang baik, yaitu hasil hutan terutama bahan kayu akan semakin berkurang dalam jangka waktu tertentu (Fathanah, 2011). Salah satu bentuk pemanfaatan kayu dari batang pohon tertentu sebagai bahan baku industri yang mempunyai prospek pemasaran dalam negeri dan ekspor yang cerah yaitu industri papan serat kayu berkerapatan sedang yang dikenal dengan Medium Density Fibreboard (MDF) (Toha, 1994 dalam Effendi, 2001).

Untuk mengatasi masalah penurunan hasil kualitas hutan maka perlu suatu alternatif pengganti kayu yang dapat menggantikan penggunaan kayu (Wulandari, 2013). Salah satu alternatif yang dapat digunakan adalah pemanfaatan bahan limbah rumput laut Eucheuma cottonii sebagai pengganti penggunaan kayu. Perekat sendiri merupakan bahan yang sangat penting di dalam pembuatan produk komposit karena dapat menentukan kualitas produk hasil rekatannya (Sulastiningsih dkk., 2013).

\section{METODOLOGI}

\section{Waktu dan Tempat}

Kegiatan penelitian ini dilakukan pada bulan April-Mei 2015 di Laboratorium Pendidikan Fakultas Perikanan dan Kelautan Universitas Airlangga, Surabaya dan pengujian sifat fisis dan mekanis MDF dilaksanakan di Laboratorium Biokomposit Fakultas Kehutanan Universitas Gajah Mada (UGM).

\section{Materi Penelitian}

Peralatan Penelitian

Alat yang digunakan untuk penelitian adalah plat besi berukuran $14 \times 13 \times 2$ $\mathrm{cm}$ sebagai frame, oven, timbangan, baskom, nampan, mesin penggilingan, mesin kempa, band saw, pengaduk, plastik transparan, penggaris, caliper, Universal Testing Machine (UTM), Wood moisture meter.

\section{Bahan Penelitian}

Bahan penelitian yang digunakan dalam penelitian ini adalah limbah rumput laut E. cottonii, perekat epoxy, serta penggunaan serbuk kayu sebagai campuran.

\section{Metode Penelitian}

Metode penelitian yang digunakan dalam penelitian ini adalah metode eksperimen.

\section{Prosedur Kerja \\ Pembuatan Medium Density Fibreboard (MDF)}

Langkah awal yang dilakukan adalah mencuci limbah rumput laut $E$. cottonii. Limbah rumput laut yang telah di- 
cuci selanjutnya dilakukan proses penyaringan dengan menggunakan saringan dan dilanjutkan proses pengeringan rumput laut menggunakan pengeringan alami dan oven hingga kadarnya mencapai 5-8\% (Hakim dkk., 2011). Limbah rumput laut E. cottonii yang telah dikeringkan dilakukan proses penggilingan untuk memperoleh rumput laut yang berupa serbuk.

Pada proses pembuatan Medium Density Fibreboard (MDF) juga ditambahkan serbuk kayu sebagai campuran dengan limbah rumput laut dengan perbandingan jumlah serbuk kayu dan limbah rumput laut sebanyak 50\%:50\% berdasarkan dari hasil penelitian Putra (2014). Limbah rumput laut yang telah berupa serbuk dilakukan pencampuran dengan perekat epoxy dengan masing-masing diberikan dosis yang berbeda.

Pembuatan MDF dilakukan dengan proses kering (dry process), yaitu dengan menggunakan pengempaan panas (hot press). Setelah bahan baku dicampur perekat, dilakukan pengempaan (pressing) dengan menggunakan kempa panas (hot press) dengan suhu $170^{\circ} \mathrm{C}$ dan tekanan 45 Pa selama 25 menit (Hakim dkk., 2011).

\section{Pengujian Kualitas Papan}

Pengujian sifat fisis dan mekanis dilaksanakan berdasarkan standar Japanese Industrial Standard (JIS) (2003) untuk papan berbasis serat. Parameter kualitas papan yang diuji adalah kerapatan, kadar air, pengembangan tebal dan daya serap air (untuk sifat fisis), sedangkan untuk sifat mekanis diuji keteguhan lentur, keteguhan patah dan keteguhan pegang sekrup (the hold strength of screw) (Batubara, 2012).

\section{Analisa Data}

Analisa data yang digunakan adalah Ana-lysis of Varian (ANOVA). Apabila didapat pemberian perlakuan menunjukkan adanya pengaruh terhadap hasil, maka akan dilan-jutkan dengan uji jarak Duncan (Duncan's multiple range test).

\section{HASIL DAN PEMBAHASAN Kerapatan}

Hasil analisis sidik ragam menunjukkan penambahan konsentrasi perekat tidak berbeda nyata $(p<0,01)$ terhadap nilai kerapatan MDF.

Dari grafik (Gambar 1.) diketahui bahwa nilai kerapatan tertinggi terdapat pada perlakuan $\mathrm{D}$ (12\% perekat) yaitu 0,65 $\mathrm{gr} / \mathrm{cm}^{3}$, sedangkan nilai kerapatan terendah terdapat pada perlakuan B (6\% perekat) yaitu $0,53 \mathrm{gr} / \mathrm{cm}^{3}$.

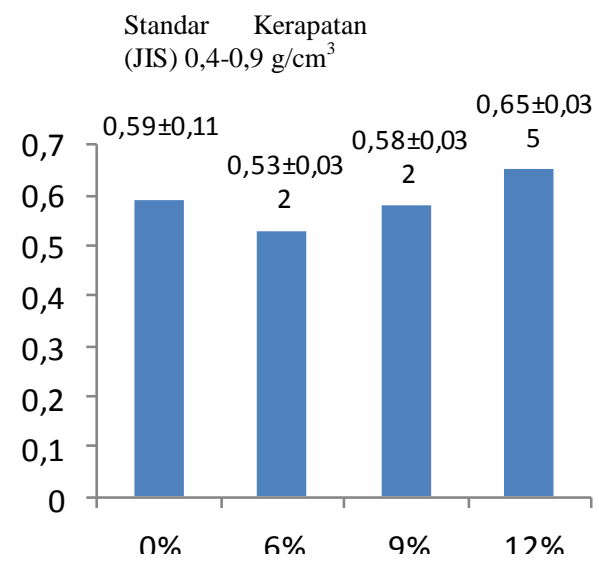

Gambar 1. Grafik kerapatan MDF dengan konsentrasi perekat berbeda

\section{Kadar Air}

Hasil analisis sidik ragam menunjukkan penambahan konsentrasi perekat tidak berbeda nyata $(\mathrm{p}<0,01)$ terhadap nilai kadar air MDF.

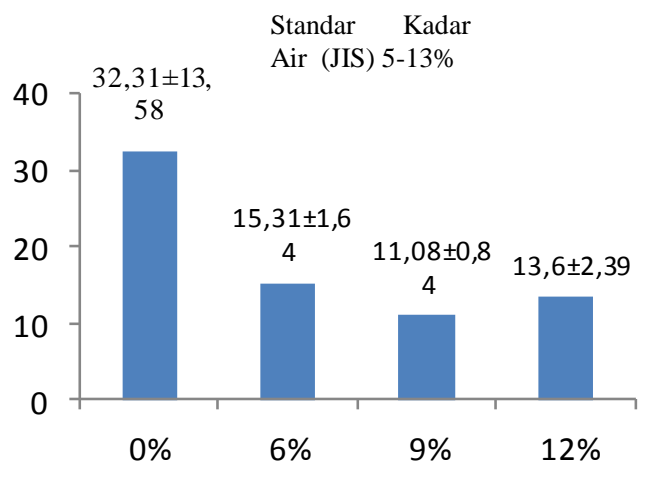

Gambar 2. Grafik kadar air MDF dengan konsentrasi perekat berbeda

Dari grafik diatas diketahui bahwa nilai kadar air tertinggi terdapat pada perlakuan A (0\% perekat) yaitu $32,31 \%$, se- 
dangkan nilai kadar air terendah terdapat pada perlakuan C (9\% perekat) yaitu $11,08 \%$.

\section{Daya Serap}

Hasil analisis sidik ragam menunjukkan penambahan konsentrasi perekat berbeda sangat nyata $(p<0,01)$ terhadap nilai daya serap MDF.

Dari grafik (Gambar 3.) diketahui bahwa nilai daya serap air tertinggi terdapat pada perlakuan C (9\% perekat) yaitu $88,11 \%$, sedangkan nilai daya serap terendah terdapat pada perlakuan A $(0 \%$ perekat) yaitu $11,35 \%$.

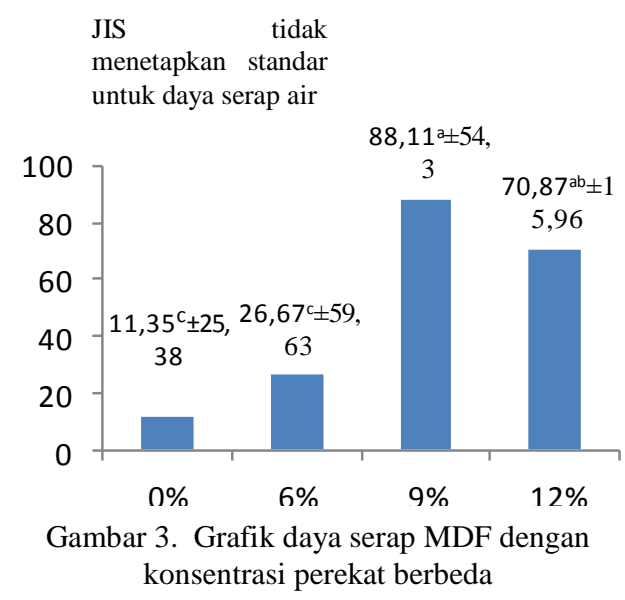

\section{Pengembangan Tebal}

Hasil analisis sidik ragam menunjukkan penambahan konsentrasi perekat berbeda sangat nyata $(\mathrm{p}<0,01)$ terhadap nilai pengembangan tebal MDF.

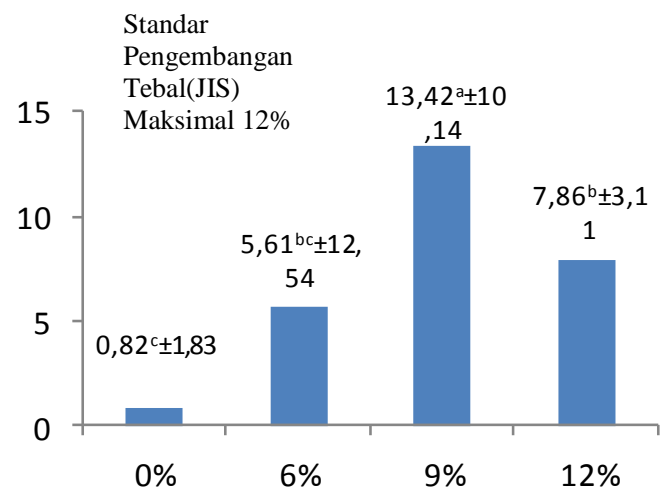

Gambar 4. Grafik pengembangan tebal MDF dengan konsentrasi perekat berbeda

Dari grafik diatas diketahui bahwa nilai pengembangan tebal tertinggi terdapat pada perlakuan C (9\% perekat) yaitu $13,42 \%$, sedangkan nilai pengembangan tebal teren-dah terdapat pada perlakuan A ( $0 \%$ pere-kat) yaitu $0,82 \%$.

\section{Keteguhan Lentur}

Hasil analisis sidik ragam menunjukkan penambahan konsentrasi perekat berbeda sangat nyata $(\mathrm{p}<0,01)$ terhadap nilai keteguhan lentur MDF.

Dari grafik (Gambar 5.) diketahui bahwa nilai keteguhan lentur tertinggi terdapat pada perlakuan D ( $12 \%$ perekat) yaitu $1,68 \times 10^{4} \mathrm{kgf} / \mathrm{cm}^{2}$, sedangkan nilai keteguhan lentur terendah terdapat pada perlakuan A ( $0 \%$ perekat) yaitu $0,47 \times 10^{4}$ $\mathrm{kgf} / \mathrm{cm}^{2}$.

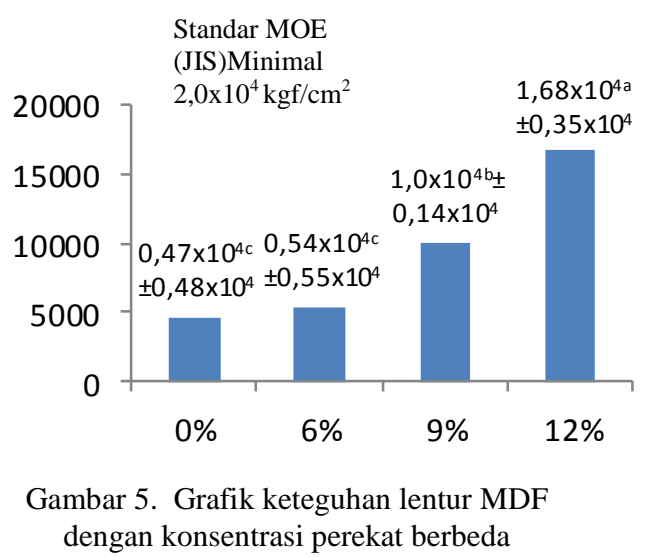

\section{Keteguhan Patah}

Hasil analisis sidik ragam menunjukkan penambahan konsentrasi perekat berbeda sangat nyata $(p<0,01)$ terhadap nilai keteguhan patah MDF.

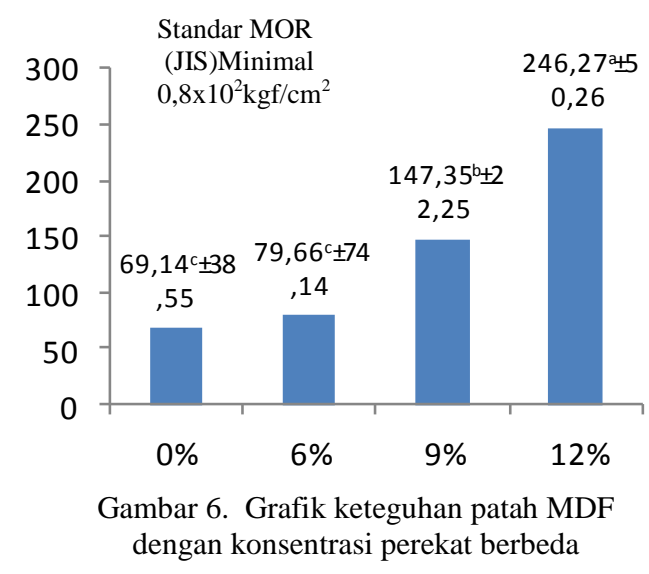


Dari grafik diatas diketahui bahwa nilai keteguhan patah tertinggi terdapat pada perlakuan D (12\% perekat) yaitu $246,27 \mathrm{kgf} / \mathrm{cm}^{2}$, sedangkan nilai keteguhan patah terendah terdapat pada perlakuan $\mathrm{A}$ ( $0 \%$ perekat) yaitu $69,14 \mathrm{kgf} / \mathrm{cm}^{2}$.

\section{Kuat Pegang Sekrup}

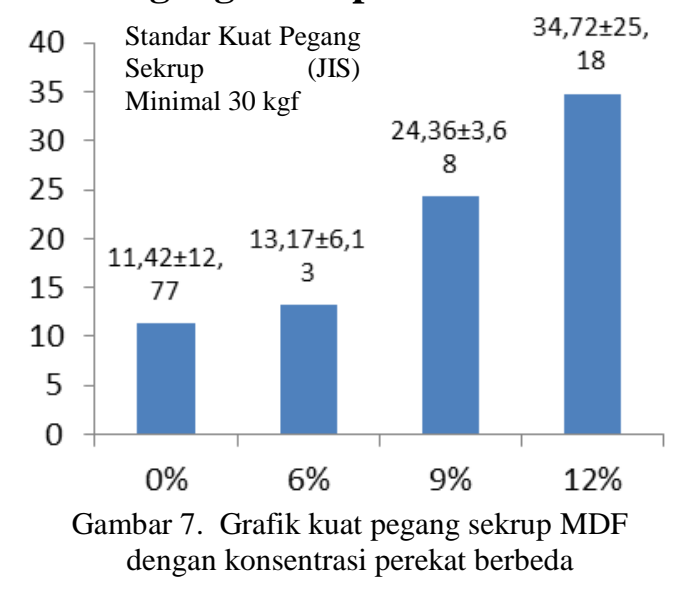

Tabel 1. Penilaian Uji Penelis
Hasil analisis sidik ragam menunjukkan penambahan konsentrasi perekat tidak berbeda nyata $(\mathrm{p}<0,01)$ terhadap nilai kuat pegang sekrup MDF. Dari grafik (Gambar 7.) diketahui bahwa nilai kuat pegang sekrup tertinggi terdapat pada perlakuan D (12\% perekat) yaitu 34,72 kgf, sedangkan nilai kuat pegang sekrup terendah terdapat pada perlakuan A (0\% perekat) yaitu $11,42 \mathrm{kgf}$.

\section{Penampakan dan Tingkat Kekerasan}

Penentuan penilaian penampakan dan tingkat kekerasan MDF didapatkan dengan cara scoring oleh panelis yang kemudian diberi score dari masing-masing perlakuan MDF. Pemberian score harus sesuai dengan kriteria penilaian berikut : nilai 1 : tidak sesuai; nilai 2 : kurang sesuai; nilai 3 : sesuai dan nilai 4 : sangat sesuai.

\begin{tabular}{|c|c|c|c|c|c|}
\hline \multirow[t]{2}{*}{ Kriteria Penilaian } & \multirow[t]{2}{*}{ Ulangan } & \multicolumn{4}{|c|}{ Perlakuan } \\
\hline & & $\mathbf{A}(0 \%)$ & $\mathrm{B}(6 \%)$ & $\mathrm{C}(9 \%)$ & $\mathrm{D}(12 \%)$ \\
\hline \multirow{5}{*}{$\begin{array}{l}\text { Penampakan } \\
\text { secara visual }\end{array}$} & 1 & 2 & 3 & 3 & 2 \\
\hline & 2 & 2 & 3 & 3 & 2 \\
\hline & 3 & 2 & 2 & 2 & 2 \\
\hline & 4 & 2 & 2 & 2 & 2 \\
\hline & 5 & 2 & 2 & 2 & 2 \\
\hline \multirow{5}{*}{$\begin{array}{c}\text { Tingkat } \\
\text { Kekerasan }\end{array}$} & 1 & 2 & 3 & 3 & 2 \\
\hline & 2 & 2 & 2 & 3 & 2 \\
\hline & 3 & 2 & 2 & 3 & 2 \\
\hline & 4 & 2 & 2 & 2 & 2 \\
\hline & 5 & 2 & 2 & 2 & 2 \\
\hline \multicolumn{2}{|c|}{ Total Penilaian } & 20 & 23 & 25 & 20 \\
\hline
\end{tabular}

\section{Penentuan Perlakuan Terbaik}

Nilai kerapatan, kadar air, daya serap, pengembangan tebal, keteguhan lentur, keteguhan patah, keteguhan rekat dan kuat pegang sekrup MDF yang mendekati kriteria JIS (Japanesse Industrial Standart) akan diberi score paling tinggi, dan sebaliknya apabila jauh dari kriteria JIS (Japanesse Industrial Standart) maka akan diberi score paling rendah. Score dari masing-masing perlakuan dijumlahkan dan diberi ranking untuk mendapatkan perlakuan terbaik. 
Tabel 2. Hasil scoring dan ranking MDF oleh panelis.

\begin{tabular}{|l|c|c|c|c|}
\hline \multirow{2}{*}{\multicolumn{1}{c|}{ Parameter }} & \multicolumn{4}{c|}{ Konsentrasi Perekat } \\
\cline { 2 - 5 } & $\mathrm{A}(0 \%)$ & $\mathrm{B}(6 \%)$ & $\mathrm{C}(9 \%)$ & $\mathrm{D}(12 \%)$ \\
\hline Kerapatan $\left(\mathrm{g} / \mathrm{cm}^{3}\right)$ & & & 2 & 4 \\
\hline Kadar air $(\%)$ & 3 & 1 & 4 & 3 \\
\hline Daya serap air (\%) & 4 & 2 & 1 & 2 \\
\hline Pengembangan tebal (\%) & 2 & 3 & 3 & 4 \\
\hline MOR $\left(\mathrm{kgf} / \mathrm{cm}^{2}\right)$ & 1 & 2 & 3 & 4 \\
\hline MOE $\left(\mathrm{kgf} / \mathrm{cm}^{2}\right)$ & 1 & 2 & 3 & 4 \\
\hline Kuat pegang sekrup $(\mathrm{kgf})$ & 1 & 2 & 3 & 4 \\
\hline Penampakan & 1 & 4 & 3 & 2 \\
\hline Tingkat Kekerasan & 1 & 2 & 4 & 3 \\
\hline Total Nilai & 15 & 19 & 26 & 30 \\
\hline Ranking & 4 & 3 & 2 & 1 \\
\hline
\end{tabular}

\section{Pembahasan}

Kerapatan MDF merupakan parameter penting yang berpengaruh terhadap pembentukan MDF, namun setelah diuji menggunakan analisis sidik ragam diketahui bahwa penambahan konsentrasi perekat tidak berpengaruh terhadap kerapatan MDF yang dihasilkan. Hal ini dikarenakan papan MDF ini dibuat dari rumput laut E.cottonii dan campuran serbuk kayu dengan perbandingan yang sama dan kandungan bahan perekat yang sama sehingga tidak berpengaruh nyata terhadap kerapatan MDF yang dihasilkan. Menurut Kelly (1977), ukuran besarnya kerapatan papan partikel dipengaruhi oleh kerapatan bahan awal, kandungan perekat serta bahan aditif yang digunakan. Berdasarkan JIS maka MDF berbahan dasar E.cottonii dalam penelitian masih memenuhi standar untuk dikategorikan sebagai papan MDF karena kerapatan yang dihasilkan berkisar antara 0,5-0,6 g/cm ${ }^{3}$.

Berdasarkan analisis sidik ragam dapat diketahui bahwa penambahan konsentrasi perekat tidak berpengaruh terhadap nilai kadar air MDF. Setiap perlakuan menghasilkan kadar air yang berbeda. Hal ini disebabkan tidak adanya perekat yang merekatkan bagian komponen partikel MDF satu sama lain maka permukaan partikel papan MDF semakin besar sehingga banyak uap air yang dapat diserap dari lingkungannya. Kadar air pada perlakuan A hasil penelitian ini belum memenuhi standar karena nilai kadar air yang diperoleh melebihi standar yaitu 32,31\% dan hanya perlakuan $\mathrm{C}$ (9\% perekat) yang memenuhi standar kadar air sesuai dengan JIS.

Pada analisis sidik ragam pengujian daya serap air diketahui bahwa penambahan konsentrasi perekat berpengaruh sangat nyata terhadap nilai daya serap air MDF. Hal ini dapat terjadi karena zat ekstraktif yang terkandung pada rumput laut lebih muda larut dalam air sehingga ikatan yang terjadi antar partikel lebih kompak dan lebih tahan terhadap air selain itu diduga karena waktu kempa yang dilakukan kurang. Hal ini sesuai dengan penyataan Puspita (2008), waktu kempa yang lebih lama akan menghasilkan ikatan antar partikel yang lebih kompak dan lebih terpadatkan sehingga ruang masuk air ke dalam papan lebih sedikit. JIS (Japanese Industrial Standard) (2003), tidak menetapkan standar untuk daya serap air. Nilai daya serap air MDF pada penelitian ini berkisar $11,35 \%-88,11 \%$.

Pengembangan tebal merupakan perubahan dimensi dari tebal kayu yang terjadi akibat perubahan kadar air dalam kayu. Dari analisis sidik ragam dapat diketahui bahwa penambahan konsentrasi perekat berpengaruh sangat nyata terhadap

Diterima/submitted: 9 Desember 2015 Disetujui/accepted: 12 Juni 2016 
nilai pengembangan tebal MDF. Pada MDF dengan perlakuan $C$ nilai pengembangan tebal melebihi standar yang telah ditetapkan JIS (Japanese Industrial Standard). Nilai standar menurut JIS mensyaratkan nilai pengembangan tebal maksimum $12 \%$ sedangkan pada perlakuan $\mathrm{C}$ bernilai $13,42 \%$. Berdasarkan JIS nilai pengembangan tebal yang telah memenuhi standar untuk dikategorikan sebagai MDF yang baik terdapat pada perlakuan A,B dan $\mathrm{D}$ dengan nilai yang berkisar $0,82 \%-7,86 \%$ dengan tidak melebihi nilai maksimum di atas $12 \%$.

Berdasarkan Gambar 5. terlihat bahwa keteguhan lentur MDF dipengaruhi oleh penambahan konsentrasi perekat. Hal ini disebabkan dengan semakin bertambahnya konsentrasi perekat yang digunakan kerekatan antar partikel menjadi lebih rapat nilai keteguhan lentur semakin tinggi. Namun pada penelitian ini nilai yang mendekati kriteria JIS terdapat pada perlakuan D sebesar $1,68 \times 10^{4} \mathrm{kgf} / \mathrm{cm}^{2}$ maka keteguhan lentur MDF berbahan dasar E.cottonii belum memenuhi standar untuk dikategorikan sebagai MDF karena nilai keteguhan lentur yang dihasilkan hanya berkisar antara $0,47 \times 10^{4}-1,68 \times 10^{4}$ $\mathrm{kgf} / \mathrm{cm}^{2}$.

Sesuai dengan analisis sidik ragam diketahui bahwa penambahan konsentrasi perekat berpengaruh sangat nyata terhadap nilai keteguhan patah. Nilai keteguhan patah MDF mengalami peningkatan seiring dengan penambahan konsentrasi perekat. Berdasarkan JIS nilai keteguhan patah yang telah memenuhi standar untuk dikategorikan sebagai MDF yang baik terdapat pada perlakuan C dan D dengan nilai yang berkisar 147,35-246,27 $\mathrm{kgf} / \mathrm{cm}^{2}$ dengan tidak di bawah nilai minimum yang ditetapkan yaitu sebesar $80 \mathrm{kgf} / \mathrm{cm}^{2}$.

Hasil analisis sidik ragam kuat pegang sekrup menunjukkan bahwa konsentrasi perekat yang tidak berpengaruh nyata. Berdasarkan JIS maka kuat pegang sekrup MDF berbahan dasar E.cottonii yang memenuhi standar untuk dikategorikan sebagai MDF yang baik pada perla- kuan D dengan nilai 34,72 kgf. Sedangkan pada perlakuan $\mathrm{A}$, B dan $\mathrm{C}$ nilai kuat pegang sekrup berada di bawah standar JIS. Hal ini dapat dikarenakan dalam pembuatan MDF yang mengakibatkan papan masih terdapat rongga sehingga kuat pegang sekrupnya relatif menurun.

\section{KESIMPULAN DAN SARAN Kesimpulan}

Penambahan perekat dengan konsentrasi berbeda pada pembuatan MDF (Medium Density Fibreboard) berbahan dasar rumput laut Eucheuma cottonii memberikan pengaruh yang nyata $(\mathrm{p}<0,01)$ terhadap daya serap air, pengembangan tebal, keteguhan lentur dan keteguhan patah, namun berpengaruh tidak nyata $(\mathrm{p}<0,01)$ terhadap kerapatan, kadar air dan kuat pegang sekrup MDF yang dihasilkan. Perlakuan terbaik terdapat pada D (penambahan perekat $12 \%$ ) dengan nilai kerapatan 0,65 $\mathrm{g} / \mathrm{cm}^{3}$, pengembangan tebal $7,86 \%$, keteguhan lentur $1,68 \times 10^{4} \mathrm{kgf} / \mathrm{cm}^{2}$, keteguhan patah $246,27 \mathrm{kgf} / \mathrm{cm}^{2}$ dan kuat pegang sekrup 34,72 kgf yang secara umum telah memenuhi standar JIS kecuali nilai kadar air dan daya serap air.

\section{Saran}

Berdasarkan penelitian yang telah dilakukan, agar pada penelitian selanjutnya dilakukan penambahan bahan yang dapat membantu menurunkan kadar air dan daya serap air sangat tinggi, agar MDF yang dihasilkan lebih baik dan didapat MDF yang memenuhi standar.

\section{DAFTAR PUSTAKA}

Batubara, R.B. 2012. Fiber-Plastic Composite dari Kertas Kardus Polietilena (PE) dengan Penambahan Maleat Anhidrida (MAH) dan Benzoil Peroksida (BP). Skripsi. Program Studi Kehutanan. Fakultas Pertanian. Universitas Sumatera Utara. Medan. 51 hal.

Effendi, R. 2001. Kajian Tekno-Ekonomi Industri MDF (Medium Density 
Fiberboard). Info Sosial ekonomi, 2 (2). hal.103-112.

Fathanah, U. 2011. Kualitas Papan Komposit dari Sekam Padi dan Plastik HDPE Daur Ulang Menggunakan Maleic Anhydride (MAH) sebagai Compatibilizer. Jurnal Rekayasa Kimia dan Lingkungan, 8 (2). hal. 53-59.

Hakim, L., E. Herawati dan I.N.J. Wistara. 2011. Papan Serat Berkerapatan Sedang Berbahan Baku Sludge Terasetilasi Dari Industri Kertas. Makara Teknologi,15(2). hal. 123130.

Japanese Industrial Standarad (JIS). 2003. Fibreboards. JIS A 5908- 2003. 28 hal.

Kasim, M. dan Asnani. 2012. Penentuan Musim Reproduksi Generatif dan Preferensi Perekatan Spora Rumput Laut (Eucheuma cottoni). Ilmu Kelautan, 17 (4). hal. 209-216.

Kelly, M.W. 1977. Critical Literature Review of Relationship between Processing Parameters and Physical Properties of Particleboard. USDA for. Serv.Gen. Tech. Rep. FPL-10. Madison, WI: USD A, Forest-Service, Forest Product Laboratory. 66 pp.

Kementerian Kelautan dan Perikanan (KKP). 2015. Komoditas Rumput Laut Kian Strategis. www.kkp.go.id. 20 April 2015. 1 hal.

Puspita, R. 2008. Papan Partikel Tanpa Perekat Sintetis (Binderless Particle Board) Dari Limbah Industri Penggergajian. Skripsi. Departemen Hasil Hutan. Fakultas Kehutanan. Institut Pertanian Bogor. Bogor. 46 hal.

Putra, G.W.A. 2014. Pemanfaatan Rumput Laut Sargassum sp. dan Eucheuma cottoni sebagai Alternatif Pengganti Serbuk Kayu untuk Pembuatan Medium Density Fibreboard (MDF). Skripsi. Fakultas Perikanan dan Kelautan. Universitas Airlangga. Surabaya. 43 hal.

Sulastiningsih, I.M.,S. Ruhendi.,M.Y. Massijaya.,W. Darmawan dan A.Santoso. 2013. Respon Bambu Andong (Gigantochloa pseudoarundinacea) Terhadap Perekat Iso-sianat. Jurnal Ilmu dan Teknologi Kayu Tropis, 11 (2). hal 140-152.

Wiratmaja, I.G., I.G.B.W.Kusuma dan I.N.S. Winaya. 2011. Pembuatan Etanol Generasi Kedua dengan Memanfaatkan Limbah Rumput Laut Eucheuma cottoni sebagai Bahan Baku. Jurnal Ilmiah Teknik Mesin Cakra M, 5 (1). hal.75-84.

Wulandari, F.T. 2013. Produk Papan Komposit dengan Pemanfaatan Limbah Non Kayu. Media Bina Ilmiah, 7 (6). ISSN No: 1978-3787. hal.1-4.

Yudohartono. 2008. Peranan Taman Hutan Raya dalam Konservasi Sumberdaya Genetik : Peluang dan Tantangannya. Informasi Teknis, 6 (2). hal.1-6. 